of a walnut, with the characteristic thrill of an arterio-venous aneurysm. An interval could be distinguished by the fingers between the tumour of the vein and the underlying artery. His chief complaint was of constant pain over the dorsum of the foot and lower part of the front of the leg. On May ' $23 \mathrm{rd}$ an incision was made over the popliteal space and the vein was tied above and below the aneurysm. The artery could not be tied at the same place as it lay deep upon the lower end of the femur and was obscured by oozing of blood. A second incision was therefore made in the usual situation for ligature of the popliteal artery at its upper end, and the artery was tied there. The patient made a good recovery, the tumour quite disappeared, and when he was discharged in August the pain in the foot had also almost gone, showing that it was chiefly due to pressure of the tumour on nerves.

CAse 2.-This case did not end so favourably. A private of the West Yorkshire Regiment was hit on Feb. 11th, 1900 , at Monte Christo by a bullet which passed through the inner border of his right thigh above its middle. On arrival at Woolwich the patient was found to have a varicose aneurysm at the upper end of Hunter's canal. On May 3 lst the femoral artery was ligatured just above its communication with the vein, and as this stopped all pulsation in the vein it was decided to postpone ligature of the latter to a substquent occasion if it should ever be necessary; such a procedure would, it was thought, interfere less with the circulation of the limb and would therefore be less likely to be followed by gangrene, which is so frequent a result of high ligature of the femoral But a few days after the operation the foot became cold and mummified and there was no alternative but to amputate the limb through the condyles of the femur. From this the patient made a good recovery, and when discharged there was no sign of an aneurysm of the vein.

$R$-marks by Lieutenant-Colonel LEWTAs.-The practice of tying both artery and vein above and below these aneurysms and then dissecting out these appears unnecessarily elaborate and severe, and the simpler operation alopted in these two cases was quite satisfactory so far as the aneurysms were conceroed.

\section{ROYAL NAVAL HOSPITAL, PLYMOUTH.} TWO CASES OF BULLET WOUNDS.

(Under the care of Deputy Inspector-General H. T. CoX, R.N.)

THe former of the following two cases is a good example of the value of suture for a divided nerve even when it is not possible to bring the two ends into exact apposition. In such cases, however, a good result is always doubtful and sometimes transplantation of a portion of nerve is advisable. In the second case an aneurysmal varix interfered seriously with the use of the limb. Any such interference is rather exceptional with this condition, but is more likely to occur in the lower than in the upper limb because the blood-pressure in the veins is greater in the former. For the notes of the cases we are indebted to Surgeon H. W. Gordon Green, R N.

CASE 1. Fracture of the humerus wath division of the musculo-spiral nerve by a Mauser bullet.-A private, aged 29 years, Royal Marine Light Infantry, H.M.S. Ponerful, was wounded in the left arm by a Mauser bulle; at Graspan on Nov. 25th, 1899. He was carrying his rifle at the slope when he received the injury. The bullet passt $d$ between the ring finger and little finger (as shown by slight skin wounds), struck the butt of his rifle, which was sent flying out of his grasp some distance away, grazed the palm of the hand, and entered the centre of the arm through the anterior and outer aepect of the biceps, fracturing the humerus and dividing the musculo-spiral nerve. He was admitted into the Ryyal Naval Hospital, Simon's Town, on Nov. 29th, where a radiograph showed extensive comminution of the humerus and lodgment of the bullet beneath the skin at the back of the arm. On Dec 4th the bullet was removed and was found to be a Mauser (ricochet) bent into a $V$ shape. The bullet was probably bent on striking the brass-bound butt of the rifle, and it now adorns the man's watch-chain. On Jan. 10th, 1900, he was discharged invalided to the s.s. Simla for passage to Kngland. The fracture bad united, a large amount of callus extending from two inches from the elbow-joint to three inches from the upper end of the bumerus having been thrown out. There was a fair amount of oedema of the forearm.
On March 5th the patient was admitted into the Royal Naval Hospital, Plymouth, under the care of Deputy Inspector-General H. T. Cox, R.N., with wrist-drop, complete motor and sensory musculo-spiral paralysis, with clamminess of the hand and wasting of the muscles. On the 20 th, the patient having been prepared for an anesthetic, the arm shaved and the skin antisepticised, chloroform and subsequently ether were administered. The arm being placed over the body a slightly oblique incision four inches in length was made half an inch behind the posterior border of the deltoid muscle which was defined, the intersection between the long and outer heads of the triceps was found, and the bone was exposed. The cicatricial tissue marking the track of the bullet could be easily traced down to the bone, and after much search the ends of the nerve were found, freshened, and sutured with catgut. Accurate apposition could not be obtained, about balf an inch of the nerve having been destroyed, but on tightening the sutures there was a gap of only about a quarter of an inch. There was troublesome hæmorrhage from the upper end of the superior profunda artery in searching for the nerve. The muscles and skin were sutured, the wound was dressed antiseptically, and a rectangular splint was applied. The temperature reached its highest point $\left(1008^{\circ} \mathrm{F}\right)$ on the $22 n d$ and was normal on the $24 \mathrm{th}$. On the 28th the sutures were removed and the wound was found to be soundly healed. On April 6th there was slight return of sensation in the back of the forearm and in the thumb. On the 18th galvanism was applied. On May 23rd the patient was discharged to 90 days' furlough. Sensation was completely restored and the hand had lost all coldness and clammivess. The muscles supplied by the musculo spiral nerve responded to the galvanic current and there was considerable increase in power in the extensors of the thumb, but wrist-drop still persisted.

CAse 2. Aneurysmal varix of the femoral artery and vein caused by a Mauser bullet-wound.-A private, aged 23 years, Royal Marine Light Infantry, H.M S. Doris, was wounded at Graspan on Nov. 25th, 1899, by Mauser bullets in the right thigh and leg. The wound of entry in the thigh was situated four inches below Poupart's ligament in the course of the femoral artery, the bullet passing directly back through the thigh, the exit wound being five and a half inches below the tip of the great trochanter. The wound of entry in the leg was situated one inch vertically below the tubercle of the tibia, apparently passing obliquely through that bone, the exit wound being at a level five inches lower down slightly to the outer side of the calf. The two bullets struck the man almost simultaneously as he was in the act of getting up from the prone firing position and they brought him to the ground. The distance from the enemy was about 300 yards, the Boers occupying a position on the face of a hill between 200 and 300 teet above the plain. There was considerable hæmorrhage from both wounds, saturating his clothing but not causing him to faint. Within a few minutes an officer of the Royal Army Medical Corps applied to the thigh wound the field dressing which he carried and five minutes later a corporal of the Royal Army Medical Curps bound up the wound in the leg. The patient was then removed by stretcher 500 yards to the rear, and thence by ambulance wagon one and a half miles to the dressingstation, where the wound in the leg was re-dressed, as it was still bleeding. From the dressing-station he was conveyed by ambulance wagon to Graspan Station Field Hospital, reaching there about five hours after being wounded. Here his wounds were dressed without bæmorrbage occurring and he remained until Nor. 27 th, when he was sent by ambulance train to the Naval Hospital, Sinon's Town, arrivirg there on Nov. 29th. On Dec. 7 th the wounds bad healed. A distinct thrill could be felt over the course of the femoral artery close to the upper wound and a loud buzzing bruit could be heard syncbrowously with the pulse. The condition of arterio-venous aneurysm was treated by rest, pressure, and elevation of the limbs, and on Jan. 10th, 1900 , the pationt was invalided home pers.s. Simla.

On March 5th the patient was admitted into the Royal Naval Hospital, Plymouth, under the care of Deputy Inspectur-General H. T. Cox, R.N. The limb was cold and slightly chematous as compared with the other and it was practically useless as regards progression, the patient being. unable to get about without the aid of crutches. The position of the wounds was as previously described. Pulsation in the posterior tibial and dorsalis pedis arteries was feeble. The bruit could be felt and heard about four inches above and 
below the scar of the entry wound, and it disappeared completely on compressing the femoral artery. There was no expansile tumour or enlargement of the veins, and the natrition of the limb was good, with slight impairment of sensation. The patient stated that immediately on receipt of the injury and for four days following he lost all sensation in the limb, but that this had improved considerably since. On April 10th, the patient having been prepared for an anæsthetic, the thigh shaved and the skin antisepticised, he was placed under ether. The limb having been rendered bloodless by Esmarch's bandage and a tourniquet applied an incision five inches in length was made in the course of the artery through the cicatrix of the bullet-wound. The urack of the bullet led down to the sheath of the vessels, passing between the femoral artery and vein, a small amount of cicatricial tissue indicating the point of injury to the coats of the vessels, binding them and the sheath together, there being direct communication between the vessels at this point. The femoral artery was isolated and ligatured with kangaroo tendon half an inch above and below the wound in the vessels, the fibrous tissue joining the artery and vein being left undisturbed. On releasing the tourniquet no pulsation or thrill could be felt in the vein. The fascia and skin wounds were sutured with catgut and silkworm gut, the wound was dressed antiseptically. and the limb was enveloped in cotton-wool and elevated, warmth being maintained by hot-water bottles. The temperature never rose above $99.6^{\circ} \mathrm{F}$. The limb and foot were quite warm and sensitive on the morning after the operation and the wound had bealed and pulsation was felt in the posterior tibial on April 19th. He was allowed to get u $\rho$ on May 1st, from which date he made an uninterrupted recovery, and was discharged to duty on June 1st with full use of the limb.

\section{Altedital Sortettiss.}

\section{OBSTETRICAL SOCIETY OF LONDON.}

\section{Adenoma of the Body of the Uterus. - Subcutaneous Sym- physiotomy.-Exhibition of Specimens.}

A MEETING of this society was held on Oct. 4th, Mr. ALBAN DORAN, the President, being in the chair.

Dr. HUBERT ROBERTS read notes of a case of Cancer of the Cervix associated with an Adenomatous Growth of the Fundus. The patient was a multipara, aged 38 years, who had advanced cancer of the cervix, the history dating from about four months before her admission. Except for discharge and bæmorrhage the patient was in good health. Though not a favourable case for vaginal hysterectomy this was performed on March 12th, 1900. The patient recovered well and was still without recurrence. The interest of the case was centred in the specimen, which showed a uterus with advanced cancer of the cervix associated with a curious growth in the fundus uteri, which proved on microscopical examination to be of an adenomatous nature and to have no connexion with the columnar-celled epithelium of the cervix. Mr. J. H. Targett and Dr. Walter Tate carefully examined the microscopical sections, which were prepared by Mr. Corrie Keep. Dr. Cosens prepared the excellent micro.photographs shown. Dr. Hubert Roberts first discussed adenomatous growths occurring in the cervix uteri, the simplest forms being erosion, mucous polypi, and the follicular hypertrophy of pregnancy. There were also some rare cases of true adenomatous tumours, which were sometimes almost indistinguishable from columnar-celled carcinoma. As regards adenoma of the body of the uterus he considered that great confusion existed. "Endometritis," so-called, was a misleading term, for although a true septic endometritis existed, many conditions called "endometritis" associated with overgrowth were really adenoma, some apparently simple, others verging on malignancy if they recurred. Reference was made to adenoma malignum in which glandular elements invaded the muscular tissues of the uterus. Such growths were clinically malignant. Mere curettings in adenoma were untrustworthy and he looked upon recurring adenomatous growtbs in the body of the uterus in old women with grave suspicions. - The Presrdent said that it was clear that two different forms of new growth had developed in the same uterus. The tumour in the body was a pure adenoma according to its microscopical appearances, but to the naked eye it looked malignant. Much remained to be learnt about the earliest stage of cancer of the uterine body.-Dr. A. H. N. Lewers said that he had met with a case presenting all the characters clinically of cancer of the cervix in which the microscopic examination merely showed large cavities lined by a single layer of columnar epithelium. Supra-vaginal amputation of the cervix was performed. For a time the patient remained well, but about a year after the operation the disease recurred in the scar, and before long there was a large typically malignant ulcer at the top of the vagina. As regards the cause why the uterus was fixed in advanced cancer Dr. Lewers believed the principal cause was extension of the malignant growth to the tissues in the neighbourhood. This seemed proved by cases where, as the impairment of mobility was only slight, an attempt was made to remove the uterus. In several such cases the operation revealed infiltrated tissue beyond the uterus at the situation where the mobility of the uterus appeared to be checked.-Dr. W. S. A. GRIFFITH remarked upon the vature and significance of peri-uterine indurations in cases of presumably operable uterine cancer.-Dr. AMAND ROUTH said he believed that any definite growth developing from the lining membrane of the uterine body after the menopause tended to become malignant and should be treated as such. He instanced a case of recurrent papilloma, innocent microscopically, in which after hysterectomy the growth was seen to have deeply invaded the muscle of the uterus. He did not consider that hysterectomy was justifiable if the broad ligament or utero-sacral folds were indurated, for as all the disease could not be removed the growth was sure to progress.-Dr. G. E. HERMAN could not agree with Dr. Griffith that fixation of the uterus in early cancer was often due to adbesions. He agreed with Professor W. J. Sinclair of Manchester that the usual direction of extension of uterine cancer was into the cellular tissue of the utero-sacral ligaments. The situation of the induration due to spread of cancer in this direction was different from that of induration from pelvic perit nitis. In some doubtful cases in which he had commenced operation, but found that there was too much extension of cancer laterally for the operation to be completed. be bad opened Douglas's pouch and found it free from adhesions. He had seen cases of large adenomatous polypoid growths in the uteri recurring again and again after removal; and the microscopical signs of such growths were distinctive; they were not solid, friable tissue like cancer, but pulpy, gelatinous translucent stuff. When such recurrence took place more than once he thought hysterectomy was indicated.Dr. HeRBERT SPENCER thought the report of the case a most valuable one. It clearly showed the association of a simple adenoma of the body with cancer of the cervix. He had no doubt that these adenomata had often been described as secondary deposits of cancer. Ruge and Veit's case ("Krebs der Gebärmutter," Fig. 34) was in his opinion erroneously so described. Cases of simple adenoma of the body had often been removed for cancer. He had met with simple adenoma in old women even recurring after curetting, and yet the patient remaining well and the uterus atrophying after as long as six years from the second curetting. The diagnosis between these cases and cancer was often very difficult.-Dr. HUBERT ROBER'TS, in reply, said he thought that in Dr. Lewers's case of suspicious recurrent adenoma of the cervix hysterectomy would have been a better proceeding than supra-vaginal amputation. He criticised Dr. Griffith's remarks and thought it was impossible clinically to decide whether fixation of a malignant uterus was inflammatory or cancerous, and he considered that if the uterus could not be drawn down by traction with a pair of volsella owing to parametric invasion it was unsuitable for operation. He considered that vaginal hvsterectomy was the best treatment for recurring adenoma of the body of the uterus in old women.

Dr. G. ERNEST Herman read a paper on Subcutaneous Symphysiotomy, pointing out the advantages of the subcutaneous operation, especially as regards its simplicity, quickness, small risk of sepsis, insignificant hæmorrhage, absence of a gaping wound and of a subsequent scar. He urged that if the maximum benefit from symphysiotomy was to be secured it should be done under the most favourable conditions. It ought not to be postponed until the necessity for some kind of operative delivery had been demonstrated by the complete failure of the natural powers. The 